Journal of Economics and Behavioral Studies

Vol. 2, No. 1, pp. 7-18, Jan 2011

\title{
Strategies for Sustainable Channel Relations in Mobile Telecom Sector
}

\author{
${ }^{*}$ Githa Heggde ${ }^{1,}$ Stuti Kumar ${ }^{2}$ \\ Welingkar Institute of Management Development and Research, Bangalore, India \\ *githa.heggde@welingkar.org
}

\begin{abstract}
The telecom sector in India largely comprises of wireless connections for phones. As of today, there are approximately 21 network providers in the country with about 7 per each circle, each offering competitive pricing to the consumers. The main objective of the study is to provide an accurate role for the company executive in developing channel relations. Further to this, the study explores the strategies which can sustain a good working relationship between the company and its channel members in the mobile telecom sector. The constructs identified for developing sustainable relationships were Setting distribution objectives, Channel design, Logistics, Image Building, Inventory management, Channel management, Payment \& credit, Promotional assistance, Setting targets, Coverage frequency, Motivating channel members to perform. The sample selected contained distributors from the Mobile telecom sector and company executives/channel managers of leading telecom companies. Factor analysis and Friedman's test was applied. The findings revealed a correlation in attitude between distributors and the executives. Motivating distributors was rated as the most important strategy by the company. The distributors felt that all channel partners needed to have positive attitude towards the channel while company executives felt that aggression made channel members perform effectively. Such findings will be of use to mobile telecom companies who are new entrants to the Indian market and to existing companies who plan to expand their coverage.
\end{abstract}

Key Words: Distribution Channels, Channel Relations, Channel management, Mobile Telecom, Distributor

\section{Introduction to Mobile Telecom Sector}

Telecom services have been recognized the world over as an important element in the socioeconomic development of a country. The cellular phone is a natural extension of the basic telephone service with an added advantage of wireless technology coupled with ease of handling, usage, and mobility. Mobile communication has contributed greatly to an increasingly competitive and close knit globe (Ravichandran, 1999).

\section{Indian Cellular Industry}

When India opened its market to mobile telecommunication, the country was divided into 23 circles. Separate licenses were given out for each of the circles in 1994. The circles were classified as Metros, $\mathrm{A}, \mathrm{B}$ or $\mathrm{C}$ depending upon the revenue potential of the circle with Metros \& A circles expected to have the highest potential (Cellular Operators of India, 2010). Today, the metro cities of Chennai, Delhi, Mumbai and Kolkata have surpassed 100\% penetration. The Indian telecom industry therefore has been shifting focus from high income metros to lower income, semi urban metros. Keeping this shift in mind, and to make the results of this study more relevant, this study was conducted in the city of Coimbatore located in the state of Tamil Nadu. Coimbatore is one of the five mini metros stretching to make it to the list of Metro cities (Indicus Analytics, 2010). Wireless telecom subscribers form majority of the chunk of the Indian Telecom industry's 600 million subscribers. The wireless subscribers number 563.73 million (Sharma, 2010). While Global System of Mobile Communication (GSM) entered India in 1992, it was only in 2005 that CDMA Code Division Multiple Access (CDMA) entered the Indian market. The early entrants into the Mobile telecom sector were MTNL, Bharti Telecommunications (Airtel) and Hutch (now Vodafone). After the telecommunication policies were revised, in order to accommodate more private operators, companies such as Tata Indicom, Idea Cellular, Aircel and Loop Mobile entered the space. The Indian market is not only the most attractive 
but also the most competitive with over seven operators in each circle. This is a phenomenon existing nowhere else in the world. The current players are Airtel, Reliance, Vodafone, BSNL (state owned), Idea, Tata, Aircel, Unitech-Telenor, Shyam-Siestema, Etisalat, Ping Mobile, S Tel, and Loop. Industry stalwarts predict that the presence of multiple mobile service providers will eventually lead to acquisitions and mergers with the big fish eating the small. In this case, providers with a wide spread and healthy distribution will definitely carry a premium. As of now the industry is faced with the challenges of Mobile Number Portability which is to be introduced by January 2010. The a priori is that, this will create a tremendous amount of churn amongst players. The ones most likely to benefit are the new entrants as consumers get to retain their existing numbers while availing attractive tariffs of the new provider.

The mobile connections market is driven by prepaid connections, which account for more than 93\% connections. The two private operators, Reliance and Tata, in less then a year had achieved more than seven million subscriber base. Reliance, the largest corporate house in India, is the leading player in this area. Channel management is very active in this sector. Mobile phone ownership in India is growing rapidly. According to the Telecom Regulatory Authority of India (TRAI), the number of telephone subscriber base in the country reached 653.92 million as on May 31, 2010, an increase of 2.49 per cent from 638.05 million in April 2010. In the wireless segment, this amounts to adding 16 million subscribers every month. The India mobile subscriber base is set to exceed 771 million connections by 2013, growing at a CAGR of 14.3 per cent in the same period from 452 million in 2009. This growth is poised to continue through the forecast period, and India is expected to remain the world's second largest wireless market after China in terms of mobile connections. (TRAI)

\section{Distribution Network}

Leading mobile telecom providers have two separate channels for prepaid and post paid connections. Within the prepaid segment, there are different channel structures for the urban and rural areas. In urban areas, the company supplies to distributor who in turn supplies to the retailer. There is a Distribution Sales Executive (DSE) attached to the distributor whose salary is sometimes reimbursed by the service provider. On the service provider end, there is a channel manager who overlooks the functioning of the channel. In the rural segment, the channel structure is similar to the urban with the addition of a sub distributor between the distributor and retailer. Post paid connections are sold via four fronts - Company owned stores, direct sales agency (DSA), and franchise and Corporate connections. All four deal directly with the company and there is no middle party. Here too, the DSA will have a DSE attached to it. Post paid connections are given only after thorough verification of the documents of the respective customers. In case of defaults, that is if customers don't pay the bill, agents are held responsible for those payments. The role of a DSE is to organize the merchandise at the outlet, take orders for SIM card requirements, and replenish recharge currency at the agency and its retailers.

The channel manager at the company's end reports to a zonal sales manager. Amongst the channel manager's duties are increasing activation, outlet, and territory expansion and generate revenue in accordance with the targets. In turn they assign individual targets to the sales persons under them. Sales persons are responsible for meeting the potential customers and getting them onto their subscriber base. Daily sales report will be submitted by every sales person to their immediate heads. Content and applications developers will be increasingly influential as the mobile retail distribution structure becomes more complex. New retail channels are being developed, with the direct channels, such as websites and on-net delivery to mobile users, growing in importance. The trend away from hardware toward data services has implications for distributors and retailers. Until recently, the mobile distribution value chain focused mainly on hardware products, such as handsets, accessories, and prepaid top-up cards but has now begun to include content services also known as valued added services. At least initially, the rise of content will mainly be made possible through the emerging direct channels, as opposed to traditional bricks-and-mortar retail outlets. Content and service providers are moving into the market with digital products, such as games and ringtones, and operators are beginning to develop new routes to the end user, all of which is developing the direct 
channel. As well as specialist direct channel players, direct services are frequently offered as part of the retail operations of companies across most mobile retail sectors.

\section{Background:}

Channel members maximize short-term profit by allocating the resources so that marginal contribution by each of the suppliers is equal to the channel members' marginal cost. Higher commission rates have diminishing returns in terms of motivating agents to devote more time to a principal. Agencies appear to spend more time than economically "optimal" (in short term) on principals with whom they have a trusting relationship and good communication. Personal contacts in the form of visits by the principal have a significant positive effect on time allocation (Anderson, 1987). Resellers often complain that their suppliers don't provide enough training and support (Cespedes, 1998). Delegation has no impact on channel profit (Couglan, 1998). Selection criteria and recruitment tools such as thoroughness, Importance, and success are used by the Channel Managers, thoroughness and performance may be improved by according greater importance to managing distribution activities (Coviello, 1989). Manufacturer support programs are related positively, though weakly to distribution intensity, when a manufacturer provides many support programs, retailers may have some incentive to join and remain in the channel system. Manufacturer coordination efforts are related inversely though weakly to distribution intensity, when close coordination is needed manufacturers are likely to limit distribution to reduce potential difficulties in channel operations and foster a supportive atmosphere in their exchange relationships. Retailer investment significantly weakens the inverse relationship between manufacturer coordination efforts and distribution intensity. Retailers making heavy investments are signaling to the manufacturers their willingness to sell and service it effectively (Frazier, 1985).

Manufacturers in heterogeneous market must ensure that the retailer interests are properly aligned. In markets with price and service competition there can be channel conflict over the nature of retail competition itself (Iyer, 1998). Quantity discounts provide an improvement over simple contracts which include fixed conditions. By linking the contract to performance such as quantity ordered for promotional spending, the incentive to achieve coordination can be created without the rigidity of fixed requirements. Manufacturer profits are constant and total profit variations are equal to retailer profit variations. Relationship between asset specificity and channel mode is significant. The probability of using an integrated channel or an intermediate mode increases relative to the independent channel (Kim, 1998). Marketing channels are frequently organized on the basis of negotiated transaction. Marketers must carefully characteristics of middleman's marketing behavior in order to avoid the risk of linking up incapable distributors (Luk, 1998). Usually the first transaction between the supplier and retailer encompasses only small quantities of goods, if these first exchanges are performed to mutual satisfaction, the number of decision variables in the internal role relations increases. The room for bargaining about the supplier's sales price will increase when the retailer's and the supplier's transaction cost is reduced (Skytte, 1992). Sales personnel most frequently named the manufacturer, owner/manager, chain management, and sales personnel as channel influencers (Speh, 1978).

While there are channel influencers, there are also influence strategies by which the source firm controls the actions of the target firm. Bandyopadhyay (2004) in his study on Indian channels elaborates that the Indian market place cannot be regarded as a seller's market anymore and therefore indirect influence strategies are used to gain compliance Indirect strategies attempt to change the perception of the target in order to get the desired behaviour. Examples of such are 1) Information exchange where the manufacturer tries to alter perception of source by discussing business interests and functioning of the supply chain without setting targets for the channel partner. 2) Recommendation is when the source sets increased targets for the channel partner by asking him to change certain behaviour and operations. If manufacturers and retailers are allowed to define their own pricing decision variable then 1) Manufacturers are indifferent about choosing among absolute prices and absolute margins and percentage margins but 2) the retailers chooses percentage margins (Tyagi, 2005). Boundary personnel (salespeople) had a significant positive effect 
on relative dealer satisfaction with the relationship. This link is a key factor in effective communication (Gassenheimer, 1996). Help the sales representative develop skills in working with middlemen to improve distribution management (Hardy Kenneth, 1988). Distribution managers would appear to favor a climate of communication ease, whereas subordinates in the distribution function would prefer a climate of cooperation. Communication and cooperation will promote salesdistribution effectiveness (Kahn et al. 2004).

Sales managers are entrenched in managing their firm's distribution channels. Sales managers are more likely than their industrial counterparts to perform the following channel management tasks: formulating channel strategies, designing marketing channels, motivating channel members, and managing conflict. However the type of product manufactured does not appear to influence the extent to which sales managers are involved in selecting channel members, coordinating channel strategy, or evaluating channel member performance. In examining the impact of firm size, Sales managers in large firms report a higher level of involvement in coordinating channel strategy and evaluating channel member performance than their counterparts in small firms (Mehta et al. 2000). Strategic alliances are cooperative arrangement that transcend organizational boundaries to achieve channel goals. Central to such alliances is an understanding by all channel members of channel goals, roles of particular players, sharing of information, cross-organization functional shifting, and a longterm commitment to the alliance. Managers at all levels in the channel have a wealth of information. This diffusion of information technology into channels is having a profound effect on how managers look at the problem of managing the channels and the resultant channel relations (Mentzer, 1993).

The following constructs were then deduced for the study

Role of company executive in developing channel relations -The variables were Setting distribution objectives, Channel design, Logistics, Image Building, Inventory management, Channel management, Payment \& credit, Promotional assistance, Setting targets, Coverage frequency, Motivating channel members to perform (Mohr, 1990, 1995).

Strategies for sustainable channel relations- In consultation with various companies the dimensions considered in the study were Motivating channel members, positive attitude towards channel, providing the channel members with market knowledge, conducive credit facility, constant and effective communication and being aggressive.

\section{Literature Review}

Distribution Channels have become the most important component of marketing today and are receiving increased attention. Channels not only add value to products and services, but also create customer and shareholder value, brand equity and market presence for a company. For most service organizations, consumer marketing and industrial marketing firms, the distribution channel, or inter organizational network of institutions, comprising of agents, wholesalers, distributors, and retailers (Gorchels et al. 2004, Pelton et al. 2002, Lambart et al. 1998) play a significant role in the flow of goods from producers to consumers. According to Cespedes (2006), demand generation, inventory storage, distribution of goods, providing credit to buyers, after sales service, product modification and maintenance are some of the functions that a channel performs. The channel member also called as an intermediary is a member of the distribution channel excluding the manufacturer and the consumer. Intermediaries come between these two and perform one or more of the above functions. The shifting of channel power from manufacturers to retailers, wholesalers, and distributors has had a great impact on distribution. When competition increases a few leading companies remain, who then become very competitive and offer high quality products. In many cases, the consumer perceives all of the top brands as substitutes for each other leading to a lower brand loyalty, which in turn decrease the manufacturer's power. This actually increases the distributor's power because sales are then determined by what is in stock and most often what is recommended by the distributor and not by what particular brand offers (Lambart et al. 1998). 


\section{Channel Relations}

Channel relations look into developing long term positive interactions between the company and the channel members. It involves more than just getting products or services from company to customer. Like all elements of marketing and operations, it offers numerous chances to improve revenue and profitability. Effective channels serve targeted customer segments, maximize sales, minimize cost and provide companies a sustainable competitive advantage. Customers are in the drivers' seats, as they should be, when it comes to the buying relationship. Powerful products and great brands no longer provide sustainable differentiation to customers. Customers are looking for superior value in all the solutions they consider. Increasingly, the channel partner creates the most powerful and sustainable differentiation in delivering superior value to customers. This focuses on the need for effective channel management. Channel management includes key decisions such as 1) Designing marketing channels, 2) Selecting channel members 3) Motivating and communicating with channel members, 4) Evaluating channel performance (Mehta, 2000, Kotler, 1999).

\section{Role of Channel Managers in Channel Management}

Channel management research and practice have now recognized the importance of managing relationships between the channel managers and firms performing distribution functions, which makes products and services available to customers at the right time and place at the right price. Channel managers are company executives who are the conduits between the company and the distribution channel. They are anyone in the firm or organization who is involved in distribution channel decision making, though in practice few firms or organizations actually have a single designated executive position called the channel manager, (Jackson 1988) (Walker, 1985) depending on the type of firm or organization, a variety of different executives are involved in making channel decisions (Rosenbloom, 1999). Often, they are the sales managers who are in constant touch with the channel partners. Channel managers play a crucial role in improving relationship with channel partners for effective functioning. They assess the channel partner's need and align goals and objectives, they motivate these resellers to attain the agreed-upon goals and provide appropriate support. Channel managers also evaluate goal alignment and reseller performance so that corrective action can be taken if necessary (Gorchels et al. 2004). This study focuses on the identifying Strategies for Sustainable Channel relations in the Mobile telecom Sector.

\section{Methods}

The study was conducted in India, Coimbatore zone. The populations of the study include all the Mobile telephone distributors and the Company executives.

\section{Sampling}

There are 4 GSM and 2 CDMA players, 4800 distributors (Cellular Operators association of India), having 260 company executives. In case of distributors, the total sample size 240 distributors from the Mobile telecom sector, out of which 120 were high performing( with Rupees 80-90 million/annum turnover, above which the areas are normally bifurcated) distributors and 120 were low performing (around Rupees 10.5 million/annum) distributors and 75 company executives/channel managers were considered.

\section{Instrument}

The primary data was collected with the help of a non - disguised well structured questionnaire based on dimensions related to channel management and a channel performance metric structure, apart from the questionnaire being used for data collection, personal discussions were also conducted with the respondents to get further Information. 


\section{Procedure}

A pilot study was conducted to understand the existing channel design in the three sectors under consideration and to define the specific statements of problem. Both primary and secondary data was collected. Primary data was as follows- initially an in-depth elite interview with top company executives, and a structured questionnaire was formulated for interviewing channel members. Secondary data was collected from books, magazines, files, and records of the company. Based on the feedback of the pilot study, a modified questionnaire was structured, for both company executives and distributors (equal number of high performing and low performing distributors were considered on the basis of sales turnover) to effectively study the gap analysis. The study was then validated by collecting data from representative cities in the States of Karnataka, Kerala, and Andhra Pradesh (Bangalore, Cochin and Hyderabad) to identify if the responses differed. In order to analyse the data with respect to the objectives of the study, several appropriate statistical methods and qualitative tests were used. The methods and tests were selected on the basis of the requirement of the problem. Following are the tests used in the study.

\section{Friedman's ranking technique:}

To assess the primary channel objectives and also the primary role of the company executives that influence channel performance, certain factors were ranked by the respondents (i.e. company executives and distributors). To get the order of ranking, Friedman's test was applied rank for each factor was obtained. This was conducted sector wise for high performing and low performing distributors separately, and also for the company executives.

Friedman's test was calculated using the formula:

$$
\mathrm{F}_{\mathrm{r}}=\frac{12}{\mathrm{IJ}(\mathrm{I}+1)} \sum_{\mathrm{i}=1}^{\mathrm{I}} \mathrm{R}_{\mathrm{i}}^{2}-3 \mathrm{~J}(\mathrm{I}+1)
$$

Where: I represented the number of samples, J was the number of columns, $R_{i}$ sum of the ranks in row 'i'

\section{Rank correlation}

Rank correlation is a technique that can be used to check whether the attitude of different respondent groups ranking an attribute is in the same direction or not. Rank Correlation is given by

$$
R=1-\frac{6 \sum D^{2}}{N\left(N^{2}-1\right)}
$$

$\mathrm{R}$ denotes rank correlation

$\mathrm{D}=$ Difference between the ranks

$\mathrm{N}=$ number of pairs given

In this research, high and low performing distributors in the different sectors and the company executives were asked to rank the factors. To find out whether their attitudes towards these factors were similar or not, rank correlation was adopted.

\section{Factor analysis}

Factor analysis is a general name denoting a class of procedures primarily used for data reduction and summarization, there may be a large number of variables most of which are correlated and which must be reduced to a manageable level. Relationships among sets of many interrelated variables are examined and represented in terms of a few underlying factors. Factor analysis is a statistical technique widely used in analyzing psychological, social sciences and business data. In business research, factor analysis is usually applied to correlation between the variables under study. 


\section{Factor Loadings}

Factor loadings are the correlation of a variable with a factor. In this research to find out the variables that are concentrated to decide the design of channel members, important roles played by the company executives from the distributor's point of view and also from the executive's point of view, and the performance metrics used by each sector, a number of variables are considered. In the way of reduction of data and to find the important variables factor analysis technique was applied.

\section{Discriminant Analysis}

Discriminant analysis is a statistical technique that classifies an observation into one of several $a$ priori groupings on the basis of observations on individual characteristics under appropriate assumptions. Discriminant analysis helps to identify the independent variables that discriminate a dependent variable for example; those who are high on the variable from those who are low on it. The classification is done by means of a linear discriminant function and the desired discriminant function is of the form $\mathrm{Y}=\lambda_{1} \mathrm{~V}_{1}+\lambda_{2} \mathrm{~V}_{2}+\lambda_{3} \mathrm{~V}_{3}+\ldots \ldots \ldots \ldots \ldots+\lambda_{\mathrm{n}} \mathrm{V}_{\mathrm{n}}$.

Where $\mathrm{Y}=$ the discriminant score

$\lambda_{1}, \lambda_{2}, \lambda_{3} \ldots \ldots \ldots \ldots \ldots . . . . . . . \lambda_{n}$ are the discriminant coefficients



In this research since the primary objective is to find out the specific variables that are important in understanding the role of company executives in channel management, discriminant analysis technique was applied.

\section{Role of Company Executives in Channel Management}

The channel managers in their profile have to perform certain functions while developing channel relations, these functions or variables are Setting distribution objectives, Channel design, Logistics, Image Building, Inventory management, Channel management, Payment \& credit, Promotional assistance, Setting targets, Coverage frequency, Motivating channel members to perform. To categorize these factors for each sector factor analysis was administered.

Exploratory factor analysis for the Mobile telecom sector was administered and the following hypotheses was formulated

$\mathrm{H}_{0}$ : Different functional variables were considered by channel managers in the Mobile telecom sector to manage channel members.

$\mathrm{H}_{1}$ : Similar functional variables were considered by channel managers in the Mobile telecom sector to manage channel members.

Table 1- KMO and Bartlett's Test for Mobile telecom sector

\begin{tabular}{ccc}
\hline \multicolumn{2}{c}{ Kaiser-Meyer-Olkin Measure of Sampling Adequacy. } & .605 \\
Bartlett's Test of Sphericity & Approx. Chi-Square & 671.701 \\
& $\mathrm{df}$ & 55 \\
& Sig. & .000 \\
\hline
\end{tabular}

Since the calculated value of significance (.000), was less than the significance level of $5 \%$, Ho was rejected, this implied that the variables correlated. KMO coefficient was checked which was .605, since this was greater than the significant value of .5 the analysis was considered sufficiently accurate. This goes to imply that in most mobile telecom companies, the channel manger works towards the same goals, in keeping the distribution channel. Eigen value table (Table 1) to check the number of factors was computed. 
Table 2 -Total Variance of Mobile telecom sector

\begin{tabular}{ccccccc}
\hline Component & \multicolumn{3}{c}{ Extraction Sums of Squared Loadings } & \multicolumn{3}{c}{ Rotation Sums of Squared Loadings } \\
& Total & \% of Variance & Cumulative \% & Total & \% of Variance & Cumulative \% \\
\hline 1 & 2.461 & 22.373 & 22.373 & 2.294 & 20.853 & 20.853 \\
2 & 2.295 & 20.865 & 43.238 & 2.238 & 20.343 & 41.197 \\
3 & 1.498 & 13.619 & 56.856 & 1.566 & 14.239 & 55.436 \\
4 & 1.146 & 10.415 & 67.271 & 1.302 & 11.836 & 67.271 \\
\hline
\end{tabular}

Since the number of factors with Eigen value more than one was four, there were four factors separable in the data. To identify which variable belongs to which factor the rotated component matrix (Table 2) was considered.

Table 3- Rotated Component Matrix of Mobile telecom sector

\begin{tabular}{|c|c|c|c|c|}
\hline & \multicolumn{4}{|c|}{ Component } \\
\hline & 1 & 2 & 3 & 4 \\
\hline Payment \& Credit & .825 & & & \\
\hline Inventory Management & .773 & & & \\
\hline Promotional assistance & -.591 & & & \\
\hline Image Building & .573 & & .502 & \\
\hline Coverage frequency & & .850 & & \\
\hline Motivating Channel members & & 695 & & \\
\hline Channel Management & & .665 & & \\
\hline Logistics & & -.525 & .524 & \\
\hline Setting targets & & & .861 & \\
\hline Channel design & & & & .847 \\
\hline Setting distribution Objective & .498 & & & .611 \\
\hline
\end{tabular}

Factor -I contained the following variables Payment and credit, Inventory management, Promotional assistance, Image building.

Factor -II contained Coverage frequency, Motivating channel members, channel management, logistics.

Factor- III contained Channel design and setting distribution objectives. Based on the component indicators the factors were renamed as follows

Factor I- Development Role

Factor II - Distribution Role

Factor III- Design Role

A channel manager is usually donning the roles of a sales manager and relationship manager of the distribution channel he manages, in a scenario, where short term benefits can be immediately realized by offering promotional schemes to channel partners, categorizing the roles of the channel mangers will give a focus to the achievement of long term channel objectives.

\section{Analysis to identify variables that discriminate high from low performing distributors}

Mobile Telecom

$\mathrm{H}_{\mathrm{o}}$ : High Performing distributors and the low performing distributors of the mobile telecom sector had the same mean discriminant function scores

$\mathrm{H}_{1}$ : High Performing distributors and the low performing distributors of the mobile telecom sector did not have the same mean discriminant function scores

Table 4 - Discriminant Wilks' Lambda statistics for Mobile telecom sector

\begin{tabular}{cccc}
\hline Wilks' Lambda & Chi-square & d.f & Sig. \\
\hline .580 & 126.798 & 11 & .000 \\
\hline
\end{tabular}


Since the calculated value of significance (.000), was less than the significance level of $5 \%$ Ho was rejected, this implied that the discriminant analysis was valid. This is to say that high performing distributors are either doing different things or doing things differently from the low performing distributors. Accuracy of the analysis was calculated using the classification table

Table 5- Discriminant Classification Results for Mobile telecom sector

\begin{tabular}{lccc}
\hline & High Performing & Low Performing & Total \\
\hline High Performing & 99 & 21 & 120 \\
High Performing & 29 & 91 & 120 \\
Low Performing & 82.5 & 17.5 & 100.0 \\
Low Performing & 24.2 & 75.8 & 100.0 \\
\hline
\end{tabular}

This table showed the classification accuracy of $79.2 \%$, hence analysis was considered accurate.

Table 6- Canonical Discriminant Function Coefficients for Mobile telecom sector

\begin{tabular}{lc}
\hline Function & Coefficient \\
\hline Setting distribution objectives & .406 \\
Channel design & -.154 \\
Logistics & -.222 \\
Image building & .766 \\
Inventory management & .277 \\
Channel management & .305 \\
Payment and Credit & .318 \\
Promotional assistance & -.979 \\
Setting Targets & .788 \\
Coverage frequency & -.391 \\
Motivating channel members & .264 \\
(Constant) & -4.319 \\
\hline
\end{tabular}

\section{The formula was}

Performance $=-4.319+\left(.264^{*}\right.$ motivating channel members $)+(-.319 *$ Coverage frequency $)+\left(.788^{*}\right.$ Setting targets $)+\left(-.979^{*}\right.$ Promotional assistance $)+\left(.318^{*}\right.$ Payment and Credit $)+\left(.305^{*}\right.$ Channel management $)+\left(.277^{*}\right.$ Inventory management $)+\left(.766^{*}\right.$ Image building $)+\left(-.222^{*}\right.$ logistics $)+\left(-.154^{*}\right.$ channel design $)+\left(.406^{*}\right.$ Setting distribution objectives $)$. The centroids were used to identify the performance level of the distributors

Table 7- Discriminant Functions at Group Centroids for Mobile telecom sector

\begin{tabular}{lc}
\hline Type of distributor & Function \\
\hline High performing distributor & .848 \\
Low performing distributor & -.848 \\
\hline
\end{tabular}

After substituting the variables, a High performing distributor will have a total closer to 0.848 .

\section{Channel Managers Strategies for Sustainable Channel Relations}

Distributors need to be continuously coaxed for sustainable relations and deliver required level of performance, there are a few factors when administered in the correct manner will enhance performance, the factors are Motivating channel members, positive attitude towards channel, providing the channel members with market knowledge, conducive credit facility, constant and effective communication and being aggressive. To identify which of these factors are highly effective, Friedman's ranking technique and rank correlation was analyzed 
$\mathrm{H}_{\mathrm{o}}$ : Channel partners and channel managers in the mobile telecom sector gave equal importance to motivating channel members, positive attitude towards channel, providing the channel members with market knowledge, conducive credit facility, constant and effective communication and being aggressive as factors for enhancing performance

$\mathrm{H}_{1}$ : Channel partners and channel managers in mobile telecom sector did not give equal importance to motivating channel members, positive attitude towards channel, providing the channel members with market knowledge, conducive credit facility, constant and effective communication and being aggressive as factors for enhancing performance.

Table 8- Friedman Test Statistics for Mobile telecom sector

\begin{tabular}{lccc}
\hline & High Performing & Low Performing & Executive \\
\hline $\mathrm{N}$ & 120 & 120 & 75 \\
Chi Square & 188.303 & 290.808 & 83.211 \\
d.f & 5 & 5 & 5 \\
Asymp.Sig, & .000 & .000 & .000 \\
\hline
\end{tabular}

From the above tables the calculated value of significance (.000) was less than the assumed significance level (.05). Hence $\mathrm{H}_{\mathrm{o}}$ was rejected. As we'll see later that, though each of the three parties place unequal emphasis on the factors, they do have a consensual direction of weight age accorded to the factors. The Chi-square High Performing Distributor $=188.303$, Low Performing Distributor= 290.808, Company Executive $=83.211$, indicating that the ranking were significant.

Table 9- Ranking of Mobile telecom sector Channel managers influence on distributors for effective performance

\begin{tabular}{|c|c|c|c|c|c|c|}
\hline & 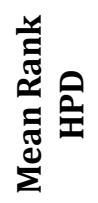 & 电 & 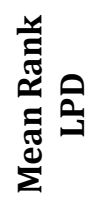 & ع & 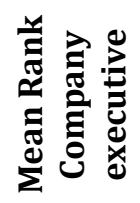 & ع \\
\hline Motivating the Channel member & 1.84 & 1 & 1.51 & 1 & 2.64 & 1 \\
\hline Positive Attitude towards Channel & 3.06 & 2 & 2.45 & 2 & 3.09 & 3 \\
\hline Provide Channel members with Market Knowledge & 4.30 & 5 & 4.90 & 6 & 4.27 & 5 \\
\hline Conducive Credit Facility & 4.85 & 6 & 4.63 & 4 & 4.83 & 6 \\
\hline Constant and Effective Communication & 3.89 & 4 & 3.90 & 5 & 3.45 & 4 \\
\hline Being Aggressive & 3.28 & 3 & 3.61 & 3 & 2.72 & 2 \\
\hline
\end{tabular}

The rank correlation is

$$
\begin{aligned}
& \mathrm{R}_{\mathrm{H}, \mathrm{L}}=0.8286 \\
& \mathrm{R}_{\mathrm{H}, \mathrm{E}}=0.9429 \\
& \mathrm{R}_{\mathrm{L}, \mathrm{E}}=0.7714
\end{aligned}
$$

The Chi-square values indicated that ranking by High performing Distributors; Low performing Distributors and Company executives were significant. Rank correlation indicates that the attitude of high and low performing Distributors had similar attitude and it also correlated with that of the channel manager's attitude. The respondent's ranked motivating channel members highest since the distribution of mobile telecom products and services is very challenging, the company needs to constantly motivate its distributors. While the distributors gave the second rank to positive attitude towards channel, the executives on the other hand considered being aggressive as the second factor that makes channel partners to perform effectively, executives felt that being forceful is requisite for performance in a highly cutthroat environment where sales targets are paramount. The gap between the high and the low performing distributors was minimum as both felt that Motivating channel members was highly important, followed by positive attitude towards channel and then being aggressive while responding to the factors by channel managers that influence performance. While 
the company executives also had similar ranking for the first as Motivating channel members, they on the other hand gave a higher ranking to being aggressive than positive attitude towards channel. The gap exists as the channel partners do not want the managers to be forceful and push the product and services, instead support them wherever required

\section{Conclusion and Recommendations}

From the study conducted, some of the findings stand out very clearly. A re-iteration of these will help us make appropriate recommendations to companies. Channel managers of all mobile telecom companies work towards similar goals. In an industry which is facing tough competition, the flaw remains that channel managers are not finding a differentiating factor to sustain their channel relations. In such a scenario, investment needs to be made in programs like 'channel members' research' and 'partner relationship management softwares'. Companies should look to hire third parties to audit processes and identify gaps in the dealings between the channel manager and its channel partners. High performing and low performing distributors function differently or with more efficiency. Apart from the systems of relationships that exist in the buying and selling of products, this difference can arise due to the superior knowledge a distributor possesses of the market place, customers, product and finally his own take from the business. In a situation where a business is having a lopsided performance of distributors, the company must intervene and re-assess the inclusion of the party in its channel. If the past performance of the distributor has been satisfactory and he has shown commitment to the company then his processes and sales force need to be audited. Sometimes distributors face a working capital crunch in which case they are not able to pay the company and as a result also fulfill pending orders. Lastly the efficacy of a distribution system can be altered and increased by monitoring pricing policies, margins, nature of product line, new products launch, servicing policies, territory of operation and sales force. An optimal combination of these should result in a satisfied consumer response.

\section{References}

Anderson, E., Lodish, M. L., Weitz, A. B. (1987), Resource Allocation behaviour in Conventional Channel. Journal of Marketing Research. 14: 85-97.

Bandhyopadhyay, S. (2004), Interfirm influence strategies within distribution channel in the emerging Indian market. Advances in Competitive Research.12(1): 1-9.

Cellular Operators Association of India, 5 June 2010, Archive Statistics, Retrieved from (http://coai.in/archives_statistics_2005_q4.htm)

Cespedes, F. V., (1988), Channel Management Is General Management. Management Review. 31(1): $98,23$.

Cespedes, F. V., (2006), Channel Management. Harvard Business Cases.

Coughlan, A. T., Wernerfelt, B., (1989), On Credible Delegation by Oligopolists: A Discussion of Distribution Channel Management. Management Science, 35(2): 226, 14.

Coughlan, T. A., Anderson, A., Stern, L. W., El-Ansary, A., (2001), Marketing Channel, New Jersey, Pearson Education, Inc,

Coviello, N., (1989), Managing Industrial Middlemen in the Small Technology-based Firm. European Journal of Marketing, 23(2): 163-174.

Forza, C., (1996), Achieving superior operating performance from integrated pipeline management. International Journal of Physical Distribution and Logistics Management, 26(9): 36-63.

Frazier, G. L., Sheth, J., N, (1985), An Attitude -Behavior Framework for Distribution Channel Management. Journal of Marketing, 49(3): 38-48.

Gassenheimer, J. B., Jay, U. S. and Robicheaux, A. R., (1996). Long-term channel member relationships. International Journal of Physical Distribution \& Logistics Management, 26(5): 94-116.

Gorchels, L., Marien, E., West, C., (2004). The managers guide to distribution channels, New York, The McGraw-Hill Companies, Inc.

Hardy, K. G., Magrath, A. J., (1988), Ten Ways for Manufacturers to Improve Distribution Management. Business Horizon. 31(6): 65, 5. 
Iyer, G., (1998), Coordinating Channels under Price and Non-price Competition. Marketing Science, 17(4): 338-355.

Jackson, D. W., Walker, B. J., (1998) The Channels Manager: Marketing's newest Aide? California Management Review, winter. 52-58.

Kahn, K.B., Richard, C. R., Joseph, O., (2004), Sales-distribution inter-functional climate and relationship effectiveness. Journal of Business Research, 57: 1085-1091.

Kotler, P., (1998), Marketing Management -Analysis, Planning, Implementation and Control, New Jersey, Prentice Hall of India Pvt Ltd.

Kotler, P., (2002), Marketing Management, New Jersey, Pearson Education Inc.

Lambart, D., Stock, J., Ellram, L. M., (1998), Fundamentals of Logistics Management, New York, Irwin/ McGraw-Hill.

Luk, T. K. S., (1998), Structural changes in China's distribution System. International Journal of Physical Distribution and Logistics Management, 28(1): 44-87.

Malhotra, N. K., (1999), Marketing Research, an applied orientation, New Jersey, Prentice Hall International Inc.

Mehta, R., Rosenbloom, B., Anderson, R., (2000), Role of the Sales Manager in Channel Management: Impact of Organizational Variables. Journal of Personal Selling \& Sales Management, 20(2): 81, 8.

Mentzer, T. J., (1993), Managing Channel relations in the 21 ${ }^{\text {st }}$ Century. Journal of Business Logistics, 14(1): 27-44.

Mohr, J., Sohi, R. S., (1995), Communication flows in distribution channels: Impact on Assessments of communication quality and satisfaction. Journal of Retailing, 71(4): 393, 24.

Mohr, J., Nevin, J. R., (1990), Communication strategies in marketing channels: A theoretical perspective. Journal of Marketing. 54(4): 36, 16.

Pelton, E. L., Strutton, D., Lumpkin, J. R., (2002) Marketing Channels, a relationship management approach, New York, McGraw-Hill Higher Education.

Ravichandran, N., (1999), Competition in Indian Industries- A Strategic Perspective, New Delhi, Vices Publishing House Pvt Ltd.

Rosenbloom, B., (1990), Motivating your International Channel Partners. Business Horizons, MarchApril, 53-59.

Shipley, D., Cook, D., Barnett, E., (1989), Recruitment, Motivation, Training, Evaluation of Overseas Distributors. European Journal of Marketing, 23(2): 79-93.

Skytte, H., (1992), Developing and sustaining competitive advantages through interorganizational relations between retailers and suppliers. International Review of Retail, Distribution \& Consumer Research, 2(2): 151, 14.

Speh, W. T., Bonfield, E. H., (1978), The Control Process in Marketing Channels: An Exploratory Investigation. Journal of Retailing, 54(1): 13-29.

Tyagi, K. R., (2005) Do strategic Conclusions Depend on how price is defined in Models of Distribution Channels. Journal of Marketing Research, 62: 228-232.

Walker, B. J., Keith, J. E., Jackson, D. W., (1995). The Channel Manager: Now, Soon or Never? Journal of the Academy of Marketing Science, summer, 82-96.

Yongkyu, K., (1998), A study on marketing channel satisfaction in international markets. Logistics Information Management, 11(4): 224-231. 